\title{
Erratum to: Demographic, Economic, Household, and Health Profile of Grandparents Responsible for Grandchildren
}

\author{
Carlos Siordia ${ }^{1}$
}

Published online: 23 July 2015

(c) Springer Science+Business Media New York 2015

\section{Erratum to: J Child Fam Stud DOI 10.1007/s10826-014-0068-4}

The article accidentally claimed GrFG refers to anyone who responded with a "yes" to the following question: Is this grandparent currently responsible for most of the basic needs of any grandchild(ren) under the age of 18 who live(s) in this house or apartment? It also states that the sample included any GRfGs at or over the age of 21 and who reside in the US mainland (contiguous states) for a total of 9,177 actual survey respondents. Instead, the analytic sample should have been described as follows: GrFG refers to anyone who reported being responsible for grandchild(dren) for less than 6 months. The sample included any GRfGs at or over the age of 21 and who reside in the US mainland (contiguous states) for a total of 9,177 actual survey respondents. GRfGs in this analysis only includes grandparents responsible for grandchildren for less than 6 months.

The author apologizes deeply for the mistake and the inconvenience caused to the readers.

The online version of the original article can be found under doi:10. 1007/s10826-014-0068-4.

Carlos Siordia

cas271@pitt.edu

1 Department of Epidemiology, Graduate School of Public Health, University of Pittsburgh, 130 North Bellefield Ave, Pittsburgh, PA 15213, USA 